\title{
Topics
}

\section{MELCO’s System Safety Management for Satellites}

\author{
By Yasushi MORI ${ }^{1)}$ \\ ${ }^{1)}$ Mitsubishi Electric Corporation, Kamakura Works, Kamakura, Japan
}

(Received June 16th, 2013)

\begin{abstract}
This paper provides an outline of Mitsubishi Electric Corporation (MELCO)'s system safety management for satellites and provides some examples according to its framework. Risk assessment, safety design order of precedence, and frequent communication and knowledge management based on the Plan-Do-Check-Act cycle are the crucial success factors of system safety management.
\end{abstract}

Key Words: Satellite, System Safety, Risk Assessment, Safety Management

\section{Nomenclature}

$X \quad$ : estimated value of severity or probability corresponding to risk category

$X_{0} \quad$ : estimated value of severity or probability corresponding to an acceptable condition

$Y \quad$ : risk point of severity or probability

$\alpha \quad$ : cognitive psychological parameter

$\beta \quad$ : cognitive psychological parameter

$$
\left(\beta=-\alpha \log X_{0}\right)
$$

$R \quad$ : risk point (equivalent to $Y$ )

Subscripts

$0 \quad$ : acceptable condition

$e \quad$ : estimation of total risk (summation form)

$s \quad$ : severity

p : probability

\section{Introduction}

"Systematic" Safety Management (System Safety Management) is essential for satellite production, test and launch site operations like satellite checkouts, and satellite and LV (Launch Vehicle) joint operations. Satellites require the use of hazardous items such as pressurized propellants, high energy batteries, and pyrotechnic devices. Furthermore, hazardous tasks like working at heights and crane operations with heavy loads are often performed in manufacturer's factory and at the launch site.

For the above reasons, launch sites all over the world have their own requirements and regulations regarding payload safety and hazardous tasks. Additionally, they request site users to prepare the necessary safety-related documents and get approval from the responsible authorities. The requirements and regulations of each launch site may slightly differ based on the managing organization and country. However, even if there is a small difference, it is more advantageous for the site user to clarify payload safety design, task plan and/or hazard control methods with the managing organization in the earliest possible phase of a project, to enable both sides to confirm whether significant problems exist and mitigate project risk as much as possible.

This paper represents the outline of system safety management and introduces some examples of actual system safety management activities.

\section{What is System Safety Management?}

"System safety" is a technical term defined in ISO14620-1:2002 Space systems, Safety requirements, System safety as: "System safety: the application of engineering and management principles, criteria, and techniques to optimize all aspects of safety within the constraints of operational effectiveness, time, and cost throughout all phases of the system life cycle"

This approach regarding "system safety" is common to major space agencies like National Aeronautics and Space Administration, European Space Agency, and Japan Aerospace Exploration Agency. Therefore, when uniting in a satellite development project, both the contractor and the contracted need to understand system safety from the beginning of a project. In the case of commercial satellites, hazardous tasks and check points have already been identified and are well-managed. Standardization of design and task procedures has been implemented to ensure compliance with safety requirements. Thus, it is important for launch site users to confirm whether any changes or revisions exist for laws, regulations, and requirements regarding safety issues.

System safety management begins with an initial risk assessment. This risk assessment is reviewed in a safety review meeting by safety experts and appropriate safety approval authorities like range safety manager or facility manager. The safety review cycle generally consists of 4 phases (Phase 0 to 3). The objectives of each phase respectively are as follows.

Phase 0 or the conceptual design phase:

a) To allocate safety requirements

b) To identify hazards and their causes

Phase 1 or the preliminary design phase:

a) To evaluate risk 
b) To review the causes of hazards

c) To review hazard prevention, reduction and control

d) To review verification methods

e) To re-check safety requirement allocations, if required. Phase 2 or the critical design phase:

a) To confirm actual design for hazard prevention, reduction and control

b) To confirm detailed method of verification

Phase 3 or the post qualification test review or acceptance test review phase:

a) To confirm the completion of verification

b) To confirm the status of action items (all closed)

Furthermore, in a launch site, the VTL (Verification Tracking Log) is followed and its closed status is confirmed before/after scheduled tasks as part of the normal pre-launch activities.

The review scope of rocket payload (satellite) includes the following items:
a) Fatality
b) Injury or occupational illness
c) Damage to launcher
d) Damage to launch site facilities
e) Pollution of the environment
f) Damage to public or private property

The type of countermeasure is chosen in accordance with safety design order of precedence as shown below.

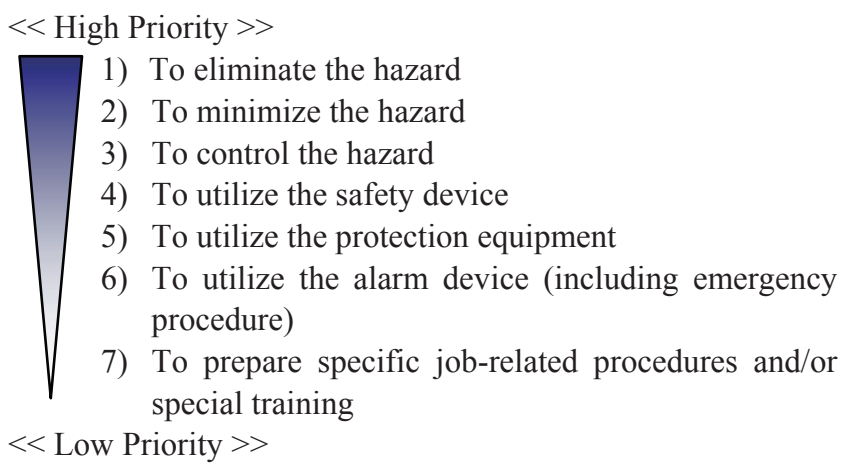

While system safety management is promoted under the above-mentioned conditions, a launch site survey and/or pre-adjustment with a person in charge will lead to smooth progress and will prevent any deviation or complications in the system safety review of each phase. The information obtained is suitable for the standardization of actual knowledge management. Moreover, the information obtained acts as a good stimulus for encouraging continuous feedback from organization members.

For this purpose, when actual system safety activities are promoted, the organization members (mainly the system engineers, QC technicians, and QA staff) are asked to join in the discussion of the standardization of system safety management.

Fig. 1 presents the standardization framework of MELCO's system safety management activities. The fundamental flow of Fig. 1 consists of the Plan-Do-Check-Act (PDCA) cycle, which is a spiral-up management flow. Additional circular arrows shown in this figure represent more timely and detailed communication to promote practical risk mitigation, and these communications provide the awareness and opportunities of standardization and knowledge management.

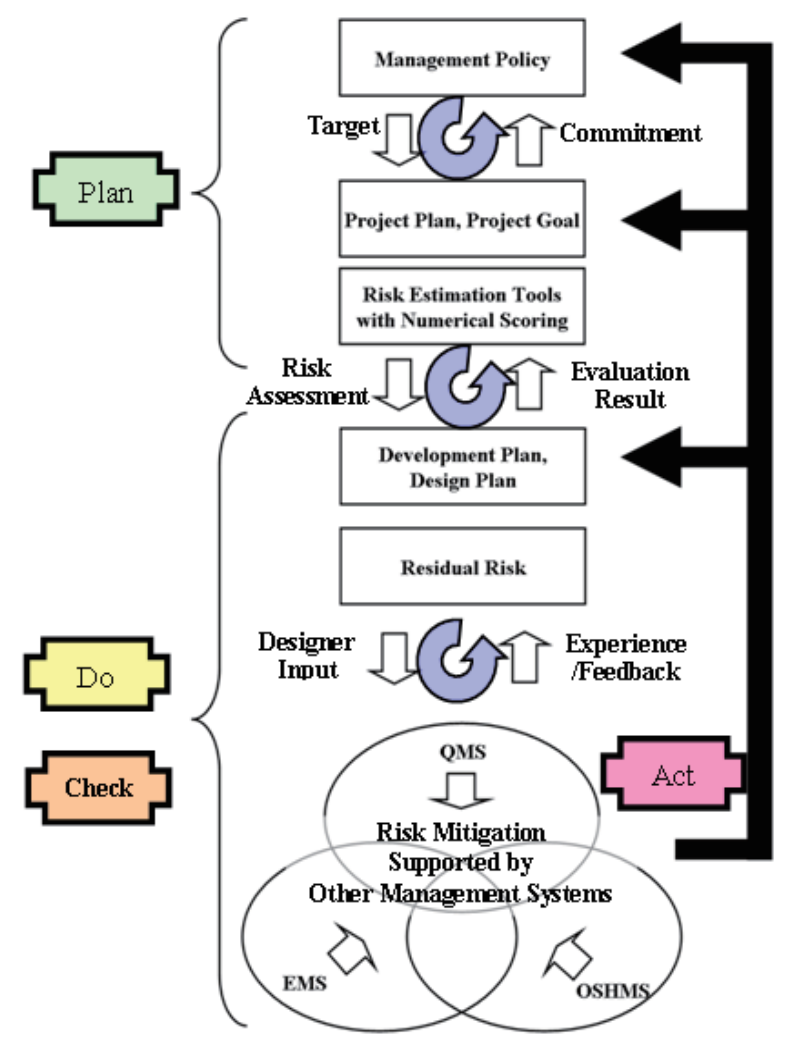

Fig. 1. The framework of MELCO's system safety management activities.

\section{Examples of System Safety Management Activities}

Each example of system safety management communications represented as circular arrows in Fig. 1 is explained below.

\subsection{Risk assessment metrics}

As explained in Section 2, the activities of system safety management begin with a risk assessment. When risk assessment is performed to identify potential hazards and evaluate risks, a qualitative risk matrix is generally used. The quantitative risk assessment of large and complex system developments is becoming a mainstream global trend for risk management. However, a qualitative risk assessment such as a preliminary hazard analysis (PHA) is extremely crucial in promoting inherent safety design in the early phases of development. Therefore, qualitative risk assessment plays an increasingly important role in complementing quantitative risk assessment. Compared with previous developments, inherent safety design is being pursued more thoroughly as product development becomes larger and more complex. On the other hand, many engineers share their workloads and have more interfaces in their projects. Under these situations, hazard identification and risk evaluation in qualitative risk assessment should be improved by using a quantified expression. Therefore, from the beginning of a project, it is very important 
to clarify the metrics of scales of "severity" and "probability" which consist in the qualitative risk matrix. The first circular arrow in Fig. 1 includes the communication and coordination between stakeholders in order to define risk assessment metrics and their acceptable levels.

An example of a quantified expression in a qualitative risk matrix is shown in "Eq. (1)", and is applied to "severity" and "probability" respectively. The estimates of "severity" and "probability" are summed in "Eq. (2)". The risk points are given so that the estimated values are not contradictory to a specified magnitude relation and given decision criteria such as "acceptable," "required to review," and "not acceptable." (Table 1 is shown as an example.) ${ }^{1)}$

$$
\begin{gathered}
Y=\alpha \log \left(X / X_{0}\right)=\alpha \log X+\beta \\
R_{e}=R_{s}+R_{p}
\end{gathered}
$$

\begin{tabular}{|c|c|c|c|c|c|c|}
\hline \multirow{2}{*}{\multicolumn{2}{|c|}{ Severity $\mathrm{R}_{\mathrm{s}}$ Probability }} & $E$ & $\mathrm{D}$ & $\mathrm{C}$ & $\bar{B}$ & $\bar{A}$ \\
\hline & & 0 & 2 & 4 & 6 & 8 \\
\hline IV & 0 & 0 & 2 & 4 & 6 & 8 \\
\hline III & 5 & 5 & 7 & 9 & 11 & 13 \\
\hline II & 8 & 8 & 10 & 12 & 14 & 16 \\
\hline I & 10 & 10 & 12 & 14 & 16 & 18 \\
\hline
\end{tabular}

Table 1. Risk pointed matrix of MIL-STD-882D
In MIL-STD-882D APPENDIX A, TABLE A-I (refer to Table 2) and TABLE A-II (refer to Table 3), each category has a suggested severity and probability in each description. These quantitative criteria are applied to "Eq. (1)" as " $X$ : estimated value of severity or probability corresponding to risk category" and " $X_{0}$ : estimated value of severity or probability corresponding to acceptable conditions" (refer to Table 4 and 5). The values of cognitive psychological parameters can be calculated by a logarithm approximation (refer to Fig. 2 and 3).

Table 4. Suggested severity and risk point, Rs.

\begin{tabular}{|c|c|c|c|c|}
\hline Severity & IV & III & II & I \\
\hline $\begin{array}{c}\text { Suggested } \\
\text { Severity, } s\end{array}$ & $2.0 \times 10^{3}$ & $1.0 \times 10^{4}$ & $2.0 \times 10^{5}$ & $1.0 \times 10^{6}$ \\
\hline Rs & 0 & 5 & 8 & 10 \\
\hline
\end{tabular}

Table 5. Suggested probability and risk point, Rp.

\begin{tabular}{|c|c|c|c|c|c|}
\hline Probability & E & D & C & B & A \\
\hline $\begin{array}{c}\text { Suggested } \\
\text { Probability } \\
\text { /ife time, } \\
p\end{array}$ & $1.0 \times 10^{-6}$ & $1.0 \times 10^{-5}$ & $1.0 \times 10^{-3}$ & $1.0 \times 10^{-2}$ & $1.0 \times 10^{-1}$ \\
\hline $\mathrm{R} p$ & 0 & 2 & 4 & 6 & 8 \\
\hline
\end{tabular}

The individual degree of risk cognition can be expressed by using these measures. Thus, a group's tendency can be determined by conducting a questionnaire survey.

Table 2. Suggested mishap severity categories. (MIL-STD-882D APPENDIX A TABLE A-I.)

\begin{tabular}{|c|c|l|}
\hline Description & Category & \multicolumn{1}{c|}{ Environmental, Safety, and Health Result Criteria } \\
\hline Catastrophic & I & $\begin{array}{l}\text { Could result in death, permanent total disability, loss exceeding \$1M, or irreversible severe } \\
\text { environmental damage that violates law or regulation. }\end{array}$ \\
\hline Critical & II & $\begin{array}{l}\text { Could result in permanent partial disability, injuries or occupational illness that may result in } \\
\text { hospitalization of at least three personnel, loss exceeding \$200K but less than \$1M, or reversible } \\
\text { environmental damage causing a violation of law or regulation. }\end{array}$ \\
\hline Marginal & III & $\begin{array}{l}\text { Could result in injury or occupational illness resulting in one or more lost work day(s), loss exceeding } \\
\text { \$10K but less than \$200K, or mitigatible environmental damage without violation of law or regulation } \\
\text { where restoration activities can be accomplished. }\end{array}$ \\
\hline Negligible & IV & $\begin{array}{l}\text { Could result in injury or illness not resulting in a lost work day, loss exceeding \$2K but less than \$10K, } \\
\text { or minimal environmental damage not violating law or regulation. }\end{array}$ \\
\hline
\end{tabular}

Table 3. Suggested mishap probability levels. (MIL-STD-882D APPENDIX A TABLE A-II.)

\begin{tabular}{|c|c|l|c|}
\hline Description* & Level & \multicolumn{1}{|c|}{ Specific Individual Item } & \multicolumn{1}{|c|}{ Fleet or Inventory** } \\
\hline Frequent & A & $\begin{array}{l}\text { Likely to occur often in the life of an item, with a probability } \\
\text { of occurrence greater than } 10^{-1} \text { in that life. }\end{array}$ & Continuously experienced. \\
\hline Probable & B & $\begin{array}{l}\text { Will occur several times in the life of an item, with a } \\
\text { probability of occurrence less than } 10^{-1} \text { but greater than } 10^{-2} \text { in } \\
\text { that life. }\end{array}$ & Will occur frequently. \\
\hline Occasional & C & $\begin{array}{l}\text { Likely to occur some time in the life of an item, with a } \\
\text { probability of occurrence less than } 10^{-2} \text { but greater than } 10^{-3} \text { in } \\
\text { that life. }\end{array}$ & Will occur several times. \\
\hline Remote & D & $\begin{array}{l}\text { Unlikely but possible to occur in the life of an item, with a } \\
\text { probability of occurrence less than } 10^{-3} \text { but greater than } 10^{-6} \text { in } \\
\text { that life. }\end{array}$ & $\begin{array}{l}\text { Unpected to occur. } \\
\text { Improbable }\end{array}$ \\
\hline E & $\begin{array}{l}\text { So unlikely, it can be assumed occurrence may not be } \\
\text { experienced, with a probability of occurrence less than } 10^{-6} \text { in } \\
\text { that life. }\end{array}$ & Unlikely to occur, but possible. \\
\hline
\end{tabular}

* Definitions of descriptive words may have to be modified based on quantity of items involved.

**The expected size of the fleet or inventory should be defined prior to accomplishing an assessment of the system. 
Additionally, the comparison between qualitative risk matrices and the adjustment of a qualitative risk matrix become possible, when required. ${ }^{2,3)}$

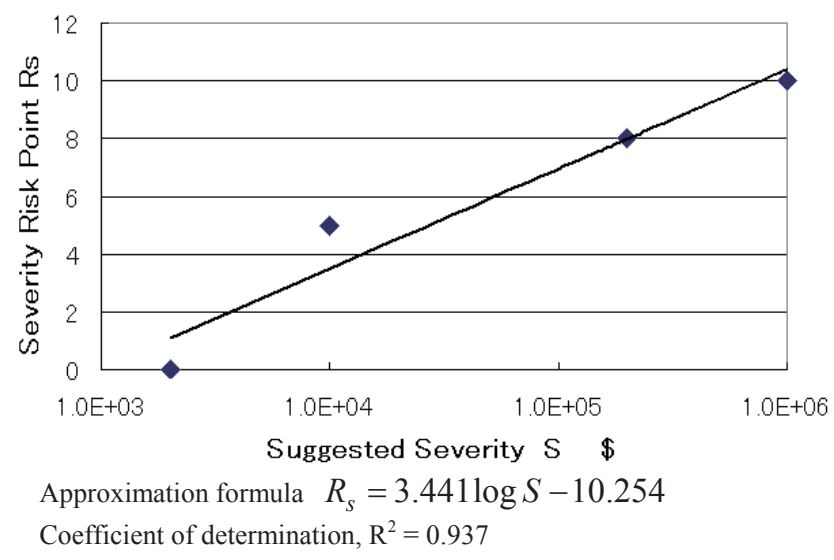

Fig. 2. Approximation formula due to suggested severity $S$ and severity risk point $R s$.

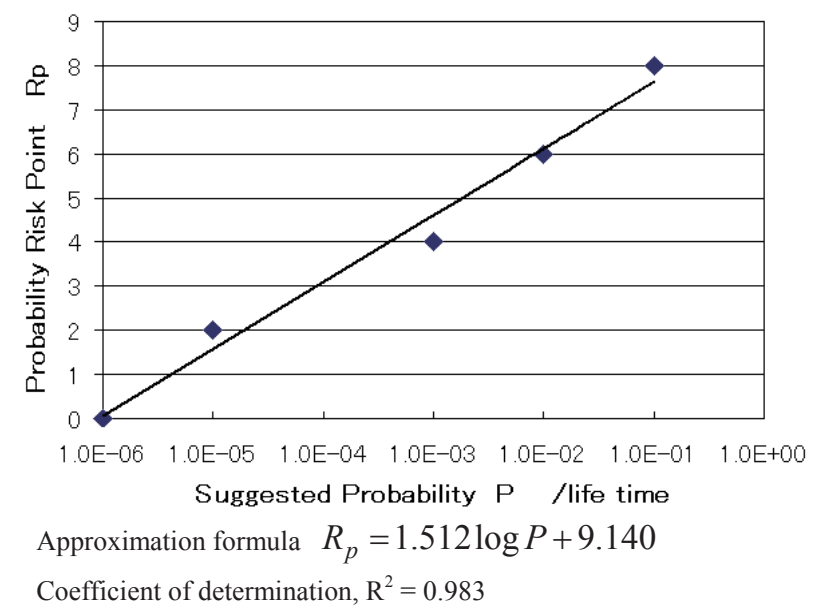

Fig. 3. Approximation formula due to suggested probability $\mathrm{P}$ and probability risk point $\mathrm{R} p$.

\subsection{FTA (Fault tree analysis)}

As an example of the second circular arrow in Fig. 1, FTA for safety analysis is shown below.

When risk assessment and its evaluation are reviewed, the confirmation of risk mitigation logic is very important. Making mitigation logic easy to understand facilitates standardization and knowledge management. Therefore, MELCO promotes the utilization of FTA during safety design and its review. Many engineers are familiar with FTA because they have experience using the technique when they perform the cause investigation of a problem. However, when engineers use the FTA technique for safety analysis, they need to be aware of the unique features and rules for using FTA for safety analysis. The "Fault Tree Handbook with Aerospace Applications"4 acts as a reference regarding FTA for safety analysis. The following guidelines are advised when performing FTA for safety analysis:

a) Steps in carrying out a Fault Tree Analysis

1. Identify the objective for the FTA.
2. Define the top event of the Fault Tree (FT).

3. Define the scope of the FTA.

4. Define the resolution of the FTA.

5. Define ground rules for the FTA.

6. Construct the FT

7. Evaluate the FT.

8. Interpret and present the results.

b) Ground Rules

1. Write the statements that are entered in the event boxes as faults; state precisely what the fault is and the conditions under which it occurs. Do not mix successes with faults.

2. If the answer to the questions, "Is this fault a component failure?" is "Yes," classify the event as a "state of component fault." If the answer is "No," classify the event as a "state of system fault."

3. If the normal functioning of a component propagates a fault sequence, then it is assumed that the component functions normally.

4. All inputs to a particular gate should be completely defined before further analysis of any one of them is undertaken.

5. Gate inputs should be properly defined fault events, and gates should not be directly connected to other gates.

As an example, the catastrophic and critical hazards of a lithium-ion battery (LIB), which were identified by a risk assessment, are shown in Table 6.

Table 6. Result of risk assessment of a lithium-ion battery.

\begin{tabular}{|l|l|}
\hline Identified Hazard & Evaluated Risk \\
\hline \hline Explosion & IE (catastrophic) \\
\hline Short, Electric Shock & IE (catastrophic) \\
\hline Contamination, Electrolyte Leakage & IIE (critical) \\
\hline Handling, Heavy Items & IIE (critical) \\
\hline $\begin{array}{l}\text { A minute amount of toxic chemicals } \\
\text { of blowout gas }\end{array}$ & IE (catastrophic) \\
\hline
\end{tabular}

The related FTA is shown in Fig. 4. In the figure, the "Pressure Relief of Battery Cell" was set as a top event because it was related to "explosion" and "a minute amount of toxic chemicals of blowout gas" among the identified hazards as shown in Table 6.

Rupture disks are expected to prevent a battery cell from explosion; however, blowout gas may cause a fire. Moreover, blowout gas contains toxic chemicals like hydrogen fluoride, benzene, and carbon monoxide. Hence, if this gas is filled in a certain volume like a temperature-controlled chamber, a small test room, or a satellite structure, workers must not approach without appropriate protective equipment.

The rising temperature of the battery cell causes an increase in the internal pressure, and hence, should be identified as a root cause to take counter measures for inherent safety design. As shown in Fig. 4, each cause of hazard can independently reach to the top event. Hence, the design of the battery should be checked to verify if the design feature can prevent the 
cause of the hazard from reaching to the top event with dual or more fault tolerant counter measures. Safety verification and abuse tests were performed to assure the validity of the counter measures. ${ }^{5)}$ Furthermore, the minimal cut sets obtained from the FTA and importance measures are useful for knowledge management.

\subsection{Cooperation with risk mitigation activities and other management systems}

As shown in Fig. 1, after the design phase, residual risk is passed on to subsequent processes such as manufacturing, test, operation, and maintenance. Communication indicated by third circular arrow in Fig. 1 is necessary for controlling residual risk. As an example of communication in the subsequent processes, transportation safety of a LIB,

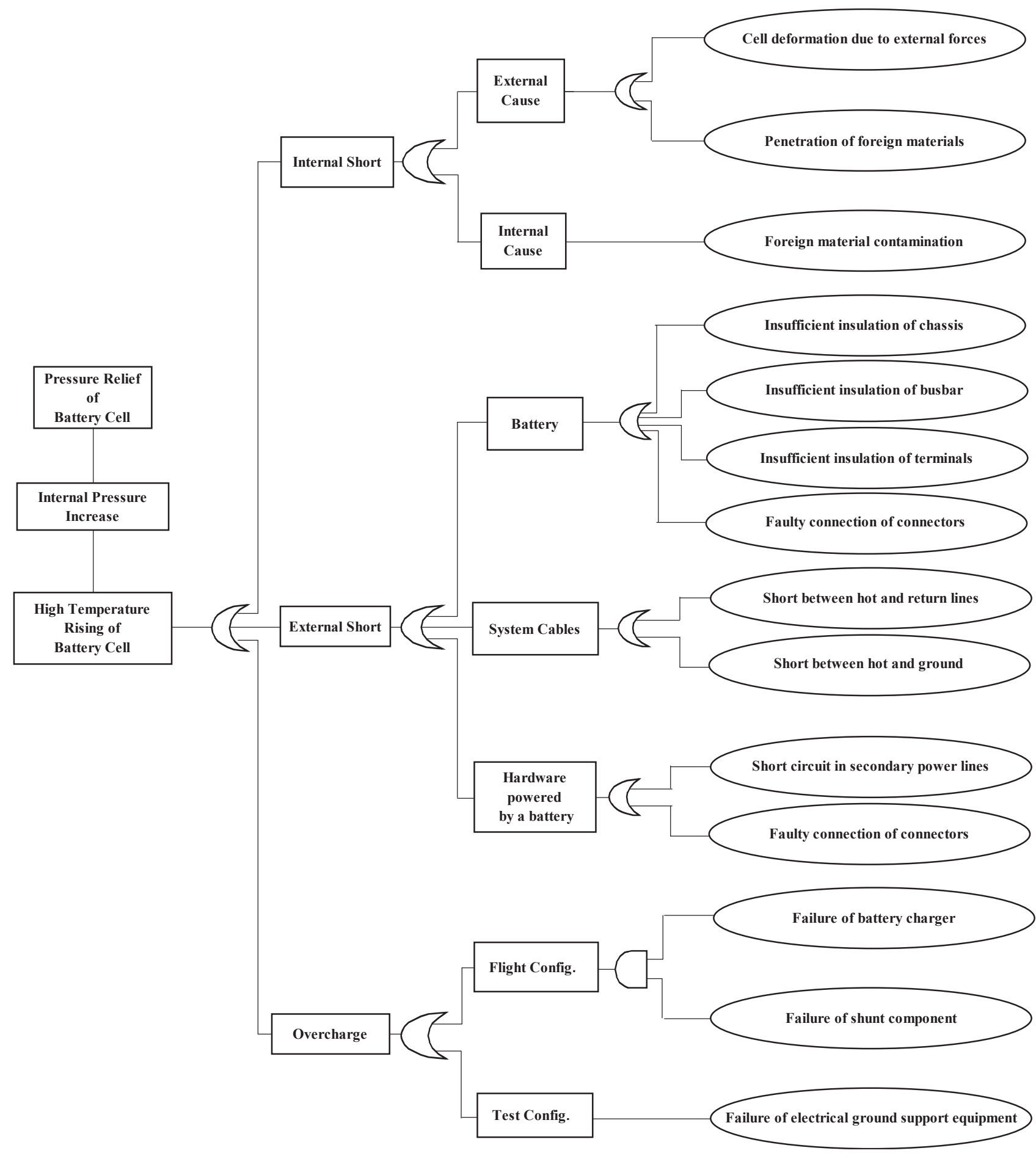

Fig. 4. The example of FTA for safety analysis: FTA related to "explosion" and "minute toxic components of blowout gas" of a LIB. 
explained in section 3.2, is as follows.

When a LIB is transported for space programs, the shipper needs to exchange information with the operator to maintain product quality. The actual transportation is carried out in a manner that eliminates risk as much as possible. It is certain that such communication has a simultaneously positive effect on safety during transportation.

In our example, in order to understand the actual transportation conditions, the shipper conducted investigations of the storage facility of the forwarder, airport warehouse, and checked their environments, procedures, and time durations of transportation and handling.

A flight schedule may change for many reasons. Consequently, the standby duration before loading the LIB into an airplane and the time of transportation also change.

Temperature and humidity conditions change with different seasons. Battery life is greatly affected by the packaging condition. Therefore, information gathering is essential for effective transportation of the LIB.

Furthermore, it is also important to check in advance regarding storage at the transit point, the handling environment, unloading/ re-loading plan, and the confirmation of package interface for forklift work.

Simultaneously, the shipper needs to provide the following information about their consignment articles:

$>$ The main characteristics of the battery

$>$ Package instructions and suitable transportation conditions

$>$ Prevention methods for external short circuit

$>$ Management of the state of charge of the battery.

Thus, the handover of a consignment product along with the exchange of pertinent information deepens the mutual understanding between concerned parties and enables them to agree upon safety conditions.

As a result of the above efforts, the risks of transportation delay and unexpected problems can be minimized and transportation safety can be maintained.

Moreover, the shipper organization should implement lessons learned through their daily work. The key points for promotion of mutual understanding are described as below:

> The shipper should always monitor the situations and trends in the physical distribution industry, and improve the knowledge level about actual transportation conditions.

$>$ Incident information should be collected by the shipper organization; safety alerts caused by incidents that affect flight schedules are especially important.

The shipper must always examine whether the product or its packaging methods comply with requirements based on the results of the incident investigations conducted by the competent authorities.

Based on this concept, CD17546 "Space systems - Lithium Ion Battery for Space Vehicle Design and Verification Requirements" was established to share basic knowledge regarding the safety measures during handling and transportation, packaging instructions, and emergency response procedure in ISO Technical Committee 20, Sub Committee 14, Working Group 1 (TC20/SC14/WG1) ${ }^{6,7)}$.

\section{Conclusions}

"Systematic" safety management is one of the essential elements of the satellite business. When using a launch site, it is important for both the site and the site user to confirm whether safety issues exist in earliest possible phase of the project. For this purpose, the site user should clearly understand safety design and risk mitigation methods. Additionally, in actual fields, cooperation with other management systems is important for the effective management of safety issues throughout the product life cycle including transportation, storage, and disposal. Therefore, risk assessment, safety design order of precedence, and frequent communication and knowledge management based on the PDCA cycle are crucial factors that lead to system safety management success.

\section{References}

1. Mori, Y. and Sugimoto, N.: Consideration on Improvement of Qualitative Risk Assessment (Quantification of Qualitative Risk Matrix for PHA), Trans. JSME series C, 75 No.759 (2009), pp.261-269.

2. Mori, Y. and Sugimoto, N.: Application in Quantification of Qualitative Risk Assessment (A Case Study of Risk Classification in Satellite Development), Trans. JSME series C, 76 No.764 (2010), pp.225-232.

3. Mori, Y. and Sugimoto, N.: Considerations on the Framework for Preventive Safety Management with Qualitative Risk Matrix (Risk Communication for an Improvement of Risk Assessment), Trans. JSME series C, 76 No.772 (2010), pp.578-585.

4. Stamatelatos, M., Vesely, W., Dugan, J., Fragola, J., Minarick III, J. and Railsback, J.: Fault Tree Handbook with Aerospace Applications, NASA HQ OSMA., (2002), http://www.hq.nasa.gov/office/codeq/doctree/fault tree.htm.

5. Mori, Y., Kiyokawa, T., Gonai, T. and Yamazaki, H.: Activities of System Safety for Satellite Developments in Mitsubishi Electric Corporation, $2^{\text {nd }}$ IAASS (International Association for the Advancement of Space Safety) Conference, Session 31 (2007).

6. Mori, Y. and Kiyokawa, T.: Introduction of Enhancement of Legal Compliance for Mitsubishi Electric Corporation / Lithium-ion Battery, $3^{\text {rd }}$ IAASS (International Association for the Advancement of Space Safety) Conference, Session 8 (2008).

7. Kiyokawa, T., Nakajima M. and Mori, Y.: Necessity of Mutual Understandings in Supply Chain Management of Lithium-ion Battery for Space Vehicle, $5^{\text {th }}$ IAASS (International Association for the Advancement of Space Safety) Conference, Part II (2011). 